\title{
Unlocking in COVID Times: The Neurosurgical Way
}

\author{
Samir Kumar Kalra ${ }^{1, \odot ~ V a n d a n a ~ K a l r a ~}{ }^{2, \odot}$ Raj Kumar ${ }^{3}$ \\ 1Department of Neurosurgery, Sir Ganga Ram Hospital \& Ganga \\ Ram Institute of Medical Education \& Research, New Delhi, India \\ ${ }^{2}$ Department of Radiology, Delhi Heart \& Lung Institute, \\ New Delhi, India \\ ${ }^{3}$ Department of Neurosurgery, UP University of Medical Sciences, \\ Saifai, Etawah, Uttar Pradesh, India \\ Indian J Neurosurg 2021;10:136-137.
}

\begin{abstract}
Address for correspondence Raj Kumar, MS, MCh, PhD, DSc, FRCS, FAMS, FNS, FASET, MRCS, MNASc, UP University of Medical Sciences, Saifai, Etawah 206130, Uttar Pradesh, India (e-mail:vc@upums.ac.in, rajkumar1959@gmail.com).
\end{abstract}

\begin{abstract}
Keywords

- COVID 19

- reverse herniation

- upwards tentorial

herniation

The humankind is facing one of the worst nightmares in the form of the ongoing Corona crisis. The pandemic has spread all across the globe and we are struggling to deal with its might. All nations have made their own strategies to deal with this situation and mainly a phase of lockdown has been the savior in most countries, especially India, where it was enforced early and well in time. After a successful lockdown, there is a phase of unlocking, which is equally important. One should exercise caution in that this should be done gradually and phased, with all the precautions in place and without any complacency. Neurosurgeons are faced with a situation pertaining to those afflicted by posterior fossa lesions with hydrocephalus. They are treated with ventriculoperitoneal shunt, but sometimes they develop reverse tentorial herniation. This needs prompt evaluation and intervention and carries a poor prognosis if untreated. Another situation is where bifrontal contusions need decompressive surgery; some patients develop encephaloceles and extradural hematomas following successful surgery and complicate the prognosis. Both situations emerge due to sudden decompression, leading to quick changes in brain pressure and perfusion. The solution is slow and careful decompression, with all precautions in place despite the temptation of eureka moments. A similar response could be desirous over the course of our unlocking period. Hope this wisdom brings us good results in these Corona times.
\end{abstract}

The COVID-19 disease has spread its wings across the world. The incidence has seen a steady rise and different locations of the world are in different stages of this pandemic. There is no place unaffected by its venom. Our country has been a late starter, but now we can see the infection rate picking up. If we analyze the strategy used by our authorities, it seems that early lockdown helped defer the speed of spread and has led to good recovery rates as well. It provided us time to prepare for a course of action which was most required. However, continuing with the lockdown could not only have far more ramifications related to economy but also prove more deleterious than the control of the pandemic itself. The unlocking

published online April 19, 2021
DOI https://doi.org/

$10.1055 / \mathrm{s}-0040-1716937$ ISSN 2277-954X. procedure has to be properly designed to serve its purpose and not lead to sudden disease spread. It is the responsibility of the citizens of the country to respond to the Government's call and not let all the efforts made so far go to waste. The unlocking has to be slow as has been, and all of us need to follow the safety norms which have been oft repeated. Sudden and massive exodus without precautions could lead to disaster and negate all efforts made till now. Remember, the battle is on but the war still needs to be won.

In neurosurgical parlance, similar analogies exist, and two of them deserve a special mention. They are reminiscent of the current crisis we all are going through. A well-described,
(C) 2021. Neurological Surgeons' Society of India.

This is an open access article published by Thieme under the terms of the Creative Commons Attribution-NonDerivative-NonCommercial-License, permitting copying and reproduction so long as the original work is given appropriate credit. Contents may not be used for commercial purposes, or adapted, remixed, transformed or built upon. (https://creativecommons.org/licenses/by-nc-nd/4.0/).

Thieme Medical and Scientific Publishers Pvt. Ltd. A-12, 2nd Floor, Sector 2, Noida-201301 UP, India 


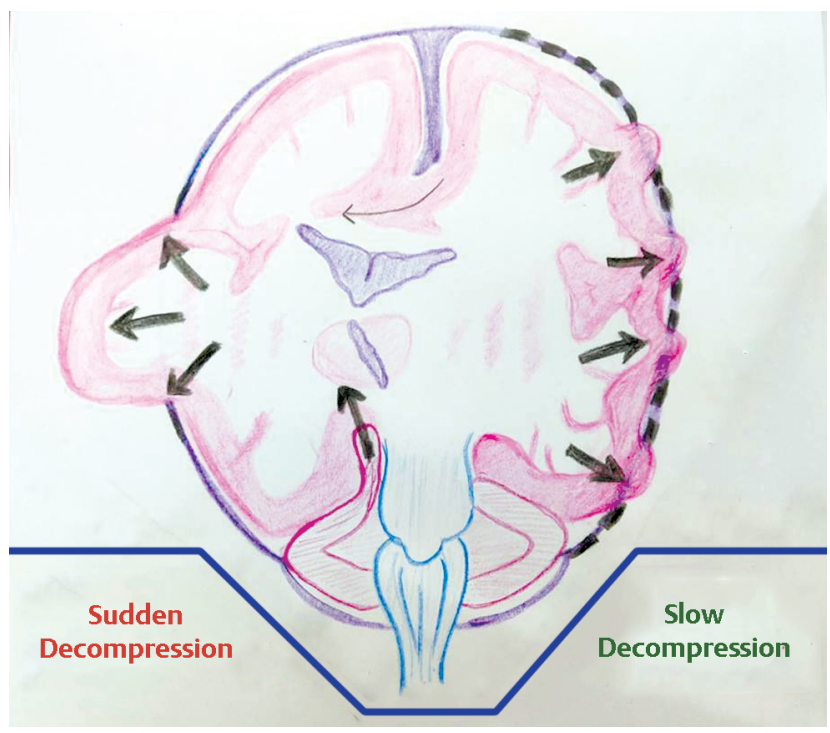

Fig. 1 Diagrammatic representation of sudden decompression and slow decompression.

albeit rare, phenomenon is that of reverse herniation or upward tentorial herniation. This occurs in situations of posterior fossa lesions with associated hydrocephalus, whereby a ventriculoperitoneal shunt is used to treat hydrocephalus. However, due to sudden decompression ( - Fig. 1 ) of ventricles, there is reverse herniation of tonsils, leading to disastrous circumstances. The phenomenon is due to double blockage of cerebrospinal fluid at aqueduct below and above at prepontine and ambient cistern, aggravating ventricular dilatation. This causes compression of veins of Galen and Rosenthal, leading to hemorrhagic infarction of brainstem. This is a neurosurgical emergency and needs immediate treatment. ${ }^{1}$ The diagnosis needs to be established, which can done with a plain CT scan of head and urgent intervention needs to be planned, based on the neurological condition of the patient. The issue here is sudden decompression leading to disastrous brain shifts and damage. Another similar situation is described in cases of severe head injured patients with bifrontal contusions requiring decompressive surgery. It is well-established that in such situations if brain decompression is done suddenly, there are high chances of associated brain shifts as well as complications like acute encephaloceles and delayed extradural hematomas. Sudden decompression produces sudden changes in perfusion of tissues and different tissues have different sensitivities to these changes. Some are able to withstand these changes and some get easily damaged. ${ }^{2}$ It is thus imperative that the decompression should be done carefully and in a staged manner. Slow decompression with intracranial pressure monitoring is preferred method for such surgeries and prevents complications.

Unlocking is also best effective if done slowly and in a staged fashion. We need to understand that all of us possess varied innate abilities to fight infections like COVID-19 and so let us not be complacent. We should look for slow release of lockdown and keep following precautions. Sudden unlocking may result in hazardous complications of massive social transmission of this dreaded virus and claim many lives, just like sudden decompression of neural structures may affect the normal brain tissue, leading to disastrous complications. Let the unlock be carefully executed and bring us hope and may we get through these difficult times unscathed.

\section{Conflict of Interest}

None declared.

\section{References}

1 Gurajala I, Brahmaprasad V, Rajesh A, Ramachandran G, Purohit AK. Reverse brain herniation following ventriculoperitoneal shunt. Indian J Anaesth 2012;56(6):585-587

2 Sun G, Shi L, Pan T, Li X, Zhang S. Technique of ICP monitored stepwise intracranial decompression effectively reduces postoperative complications of severe bifrontal contusion. Front Neurol 2016;7:56 